\title{
Ocular status of children with disabilities in special schools in southern district of Cross River State, Nigeria
}

\author{
Ernest E. I. ${ }^{1}$, Chigozie U. I. ${ }^{2}$, Roseline E. N. ${ }^{3}$, Stanley O. ${ }^{4}$ \\ ${ }^{1}$ Ernest Ikechukwu Ezeh, Department of Ophthalmology, ${ }^{2}$ Chigozie Ikechukwu Uzomba, Department of Paediatrics, \\ ${ }^{3}$ Roseline Nkeiruka Ezeh, Department of Ophthalmology, ${ }^{4}$ Stanley Onyemelonu OD, Department of Ophthalmology; \\ authors $^{1 \& 2}$ are affiliated with of Calabar, Calabar, Cross River State, Nigeria. authors ${ }^{3 \& 4}$ are affiliated with University \\ of Calabar Teaching Hospital, Calabar, Cross River State, Nigeria.
}

Corresponding Author: Ernest Ikechukwu Ezeh, University of Calabar, Calabar, Cross River State. E-mail: ezehiyk@yahoo.com

\begin{abstract}
Introduction: Good ocular health is paramount for optimal childhood development. Vision, which is the primary function of the eyes, plays a fundamental role in the acquisition of skills such as language, interpreting facial expressions and skills requiring hand-eye coordination.In every child, much of knowledge and skills are obtained through the senses of sight and hearing.For children with disabilities, vision has been noted to play an integral role in their psychosocial development, as well as compensates for certain impaired functions. The objective of this study was to determine ocular status of children with disabilities other than visual disabilities attending special schools in Calabar, Cross River State, Nigeria. Subjects and Methods: A cross-sectional study on the ocular status of children with disabilities other than visual disabilities attending special education schools in Calabar Municipal Local Government Area, Southern district, Cross River State, Nigeria was performed. Data were obtained using interviewer-administered questionnaires on the caregivers and ocular examination of the children which included visual acuity, refraction, ocular alignment, motility tests and funduscopy. Data analysis was performed using the Statistical Package for the Social Sciences version 20. Results: A total of 161 children with disabilities (other than visual disabilities) out of the 176 enrolled were examined yielding a $91.5 \%$ response rate. The male-to-female ratio was 1.2:1. Their age range was 5-17 years with the mean age of $12.9 \pm 3.3$ years and a modal age group of $\geq 13$ years. The common types of disability encountered were hearing disability 45 (28\%), developmental disability 38 (24\%) and multiple disabilities 35 (21.9\%). 71\% of the children had at least one form of ocular disorder. The most common ocular disorders seen in these children were refractive errors (46.1\%) and optic atrophy (12.0\%). Of the 161 children examined, only $11(6.8 \%)$ have had ocular evaluation in the past. Conclusion: Ocular disorders are common in children with other disabilities. However, only a few are opportune to have ophthalmic evaluation. Therefore, strategies regarding increasing awareness, mandatory ocular examination and early detection as well as treatment of the ocular disorders are urgently needed.
\end{abstract}

Keywords: Optic atrophy, Developmental disability, Learning disability, Refractive error, Disability, Visual impairment

\section{Introduction}

The term disability is a fundamental event in an individual that confers the status of impaired functionality. It refers to the presence of impairments, activity limitations, and participation restrictions, which are caused by abnormal changes in various sub-systems of the body. A disability may be present from birth (congenital), or can occur during a person's lifetime (acquired). The degree of disability may range from mild to moderate, severe, or profound; and an individual

Manuscript received: $30^{\text {th }}$ April 2019

Reviewed: $10^{\text {th }}$ May 2019

Author Corrected: $17^{\text {th }}$ May 2019

Accepted for Publication: $21^{\text {st }}$ May 2019 could have more than one disability concurrently. The seven common types of disabilities in children are visual impairment, hearing impairment, physical disability, developmental disability, mental disability, speech disability and learning disability. Each disability affects the overall development of a child but if he/she has multiple disabilities, the negative impact on quality of life increases manifolds [1,2]. Children with disabilities constitute a critical part of the population. According to the World report on disability, estimated 25 million Nigerians had at least one disability, and about 1.3 million of these persons with disability are 


\section{Original Research Article}

children [2]. Vision, which is the primary function of the eyes, plays a fundamental role in the acquisition of skills such as language, interpreting facial expressions and skills requiring hand-eye coordination [3]. It plays an important role in the development and functioning of a child. In every child, much of knowledge and skills are obtained through the senses of sight and hearing [4]. For children with disabilities, vision has been noted to play an integral role in their psychosocial development, as well as compensates for certain impaired functions $[5,6]$; particularly in children with hearing impairment [6].

When either sight or hearing is seriously impaired, the other is used to compensate. As the degree of impairment increases in one sense, the role of the remaining sense becomes progressively more significant [7]. That is, ahearing-impaired child compensates by making greater use of the eyes, and vice-versa; hence, even a mild ocular problem may reduce visual efficiency as well as the overall functionality of the child $[4,7]$.

Therefore, any unrecognized and untreated ocular abnormality in children with disabilities other than visual disabilities will adversely affect their development, psychosocial behaviour and learning potentials, to a very large extent, thereby, adding further socioeconomic burden on the family [3,8]. Similarly, the persistence of an untreated ocular abnormality would exponentially aggravate the impact of other forms of disability [9].

Furthermore, if a child continues to have an uncorrected visual deficit beyond the age of 10-12 years, the plasticity of the visual system is lost, and the recovery of vision can be limited [10]. Hence, the need for a timely and comprehensive ophthalmic assessment in this group of vulnerable children. Children with disabilitieshave been reported to be at a higher risk of ocular and visual problems than their peers $[5,6,11]$.

However, they often cannot communicate symptoms adequately. Frequently, these children with disabilities who have ocular problems may be unable to express the presence of symptoms [5,9]. Furthermore, their ocular problems are often overlooked, as the main focus always remains on their primary disability.

They may receive various interventions through their schools systems (special education schools) including occupational, physical and/or speech therapy, but in most cases, they do not receive a comprehensive eye and vision examination [9]. Additionally, the ocular evaluation in these children is a challenge and requires patience, skills and a broader range of assessment instruments [12]. Thus, the aim of this study was to assess the ocular state of children with disabilities other than visual disability, with a view to sensitizing professionals who handle these children as well as stimulate policy makers.

\section{Subjects and Methods}

Study setting: The Study schools consisted of three special education schools in Calabar, a major city in the Southern district of Cross River State, Nigeria. These schools educational approach was the "Segregation approach model", that is, the children with disabilities were not attending same classes with non-disabled but had their designated classes.

Study type: It is a descriptive cross-sectional study.

Sampling Methods: One hundred and seventy-six school-age children (5-17 years) with various disabilities other than visual disability attending the three special education schools in Calabar, Cross River State, were consecutively recruited for the study. These were two privately owned special schools and a Government-owned (Public) special school.

\section{Inclusion criteria}

- Children aged 5 to 17 years with disabilities attending the special education schools in Calabar.

- Whose Parents/Guardian consents' to participate in the study.

- And the child assents' and is able to co-operate with the clinical evaluation process.

\section{Exclusion criteria}

- Those children whose primary disability was visual impairment.

- Refusal of participation by Parents/Guardians.

- A child with disability who does not assent.

- A child with disability who is unable to co-operate with the clinical evaluation process.

Ethical consideration and permission: Institutional ethical approval was obtained from the Health Research and Ethics Committee (HREC) of University of Calabar Teaching Hospital (UCTH). Permission for the study was further obtained from the State Ministry of Education. Prior permission was also sought from the 
management of the respective special schools. We adhered strictly to the United Nations Convention on the Rights of Persons with Disabilities [13] particularly articles 7, 10,21-26 and 31 as well as international ethical guidelines for biomedical research involving vulnerable subjects - guidelines 13, 14 and 15[14].

Data Collection: The research team comprising of Ophthalmologist, Paediatrician, Optometrist, and Research assistant visited the special schools. The examination process was explained to the teachers and parents through a letter of introduction.

Written informed consent was obtained from each child's parent or guardian, through the school authority, before enrolment into the study.

The willing cooperation (assent) of the child was also sought, after the child had been informed to the extent that the child's maturity and intelligence permitted.

Relevant history regarding the type of disability, birth history, family history and history of consanguinity was recorded. Depending on the child's resolution or recognition ability, the presenting visual acuity was assessed using appropriate chart (Tumbling E chart at 6 $\mathrm{m}$ distance or Lea symbols chart or Teller acuity cards held at 40 centimetres) for age and intellectual maturity.

Refraction was done on all participants using a Ryuskoauto refractor (Ryusko, Japan GR-3100K, SN 38 AL 2766).

The result from the autorefraction was used as the starting point for a full subjective refraction. For children with visual acuity $<6 / 18$, cycloplegic refraction was done using cyclopentolate $1 \%$ as the dilating agent after ascertaining that the child didn't have seizures. In case of history of seizures, $1 \%$ tropicamide eye drops were used. The type of refractive error was recorded. Myopia was defined as spherical equivalent of less than or equal to -0.5 diopter, Hypermetropia as more than or equal to +1.0 diopter and Astigmatism as more than or equal to \pm 0.5 diopter.

One drop instilled into the conjunctival sac every $5 \mathrm{~min}$ $\times 2$ doses and allowed for 25-30 min before refraction was done. Hirshberg light reflex test and cover uncover test was used to evaluate visual axis and strabismus. Ocular movements were tested and presence of nystagmus was checked.

Anterior segment was examined using torch light and magnifying loupe of $6 \mathrm{X}$ to rule out any abnormalities of eyelids, conjunctiva, cornea, anterior chamber, iris and lens. Direct and consensual papillary light reflexes were also checked.

A detailed fundus examination after dilatation was done by direct ophthalmoscope either after cycloplegic retinoscopy or after dilating the pupils with $1 \%$ tropicamide eye drops. Children requiring further evaluation and treatment were referred to the Children eye clinic, UCTH.

Data Analysis: Data were analysed using the Statistical Package for the Social Sciences (SPSS) for Windows (version 20, SPSS inc., Chicago, IL, USA).

Descriptive statistics (frequencies, percentages, mean and standard deviation) were used to summarise the variables.

\section{Results}

Demographic features- A total of 176 children with special needs were enrolled in the study. The distribution by schools was 62 children (35.3\%) from privately owned special schools and 114 children (64.7\%) from Government Special education school.

One hundred and sixty-one children were recruited and evaluated, giving a response rate of $91.5 \%$. The age range was $5-$ 17 years with the mean age of $12.9 \pm 3.3$ years and modal age group was $\geq 13$ years $(59 \%)$. Of the 161 participants, 87 $(54 \%)$ were male and $74(46 \%)$ were female giving a male-to-female ratio of 1.2:1.

Distribution of disabilities- A total of 114 (71\%) had single disability and $47(29.2 \%)$ had multiple disabilities. The common category of disability encountered was hearing disability 45 (28\%) and developmental disability (DD) 38 $(24 \%)$.

The combinations of the multiple disabilities were $35(21.9 \%)$ with hearing loss-speech disability, and DD-speech disability 4 (2.5\%). Others were learning disability (LD)-speech disability, physical disability-speech disability, DDmental disability, and hearing loss-physical disability, with $2(1.2 \%)$, respectively. Figure 1 shows the distribution of the children according to type of disabilities. 


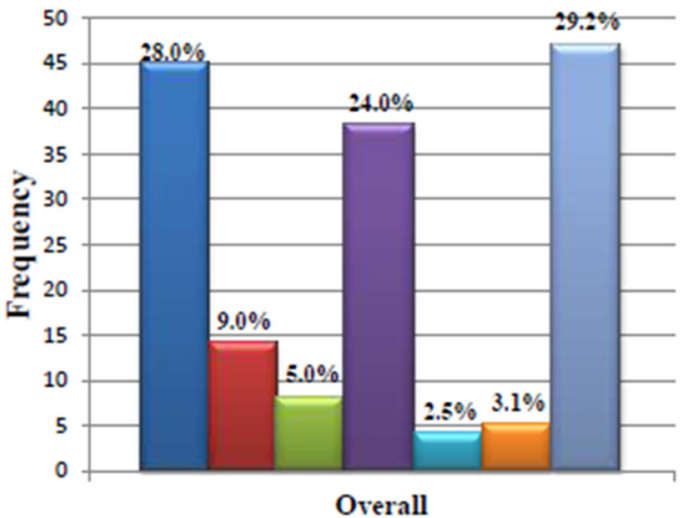

घearing disability

घearning disability

$\llbracket$ Physical disability

$\square$ Developmental disability

$\llbracket$ Mental disability

\Speech disability

Multiple disability

Figure-1: Distribution of children according to disabilities

Pattern of the ocular disorders- $71 \%$ of the children had at least one form of ocular disorder. The most common ocular disorder observed in the study was refractive errors, present in $46.1 \%$ children. Optic atrophy was the second most common finding, seen in $12.0 \%$ children. Figure 2 shows the distribution of ocular disorders in details.

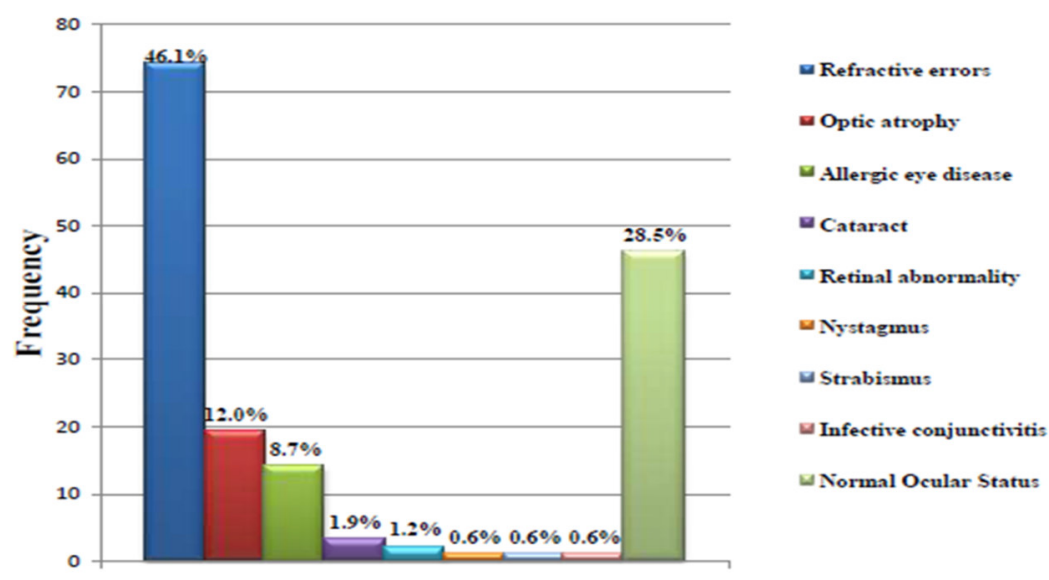

Figure-2: Frequency of ocular disorders in children with disabilities

Astigmatism accounted for $86.0 \%$ of the refractive errors, while hyperopia and myopia accounted for $12.0 \%$ and $2.0 \%$ respectively [Figure 3]. Only $11 \%$ of the children with refractive errors were using spectacle corrections as at examination time.

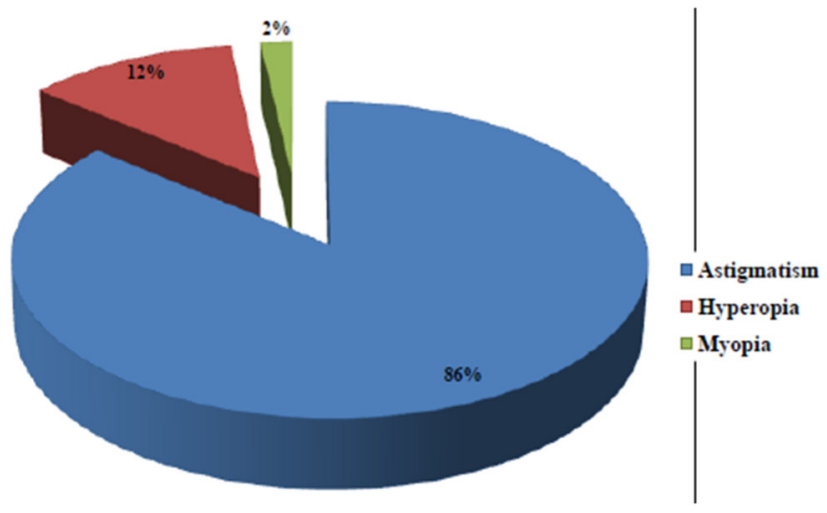

Figure-3: Distribution of refractive errors 
Eye health seeking behavior: Only $9.9 \%$ of the children communicated the presence of eye symptoms. About $93.7 \%$ of children with eye complaints, $68.1 \%$ of those without eye complaints, and $73.7 \%$ of those who don't know if they had eye complaints were observed to have at least on form of ocular disorder.

One hundred and forty-eight 148 participants responded to the question on previous ocular assessment, only 11 (6.8\%) have had their ocular and visual status assessed in the past.

Reasons given for not having had a previous eye check were 'the parents or caregivers did not feel the need for an eye check (65.2\%)', 'that neither the child's teacher (18.5\%) nor the child's doctor $(5.9 \%)$ had recommended an eye check', 'cannot afford an eye check (2.5\%)', 'an eye check will increase the cost of care for my child (4.3\%)' and 'my type of child cannot be examined by the eye doctor $(1.9 \%)$ '.

\section{Discussion}

Children with disabilities (other than visual) are vulnerable children, prone to social, educational and health neglect $[5,15]$. They are entirely dependent on the visual inputs for their personal and educational needs[12] unfortunately they are at a higher risk of ocular and visual problems than their age matched, apparently normal children $[5,6,16,17]$.

This study showed the presence of ocular problems in $71 \%$ children with other disabilities. The high frequency of ocular abnormalities found in this study is consistent with similar studies in different regions of the world, which had reported frequencies ranging from $31 \%$ to $96 \%$, among children with disabilities [16-23]. It is well documented that these children are at greater risk of oculo-visual disorders than typically normal children [57, 11]. Refractive errors and optic atrophy were the most common ocular disorders identified in our study. This agrees with other studies that refractive errors are most common ocular findings in children with other disabilities $[4,16,21,23,24,25]$. Though most study had reported strabismus as the second common ocular disorder in this children $[3,7,11,12,26,27]$ our study identified optic atrophy as the second common ocular disorder in this children. Notably, these conditions are neurologically related thus this may suggest the existence of a background neurologic dysgenetic process in these children with disabilities.

Astigmatism was found as the most common type of refractive errors in the children studied. This is at variance to some studies that found hyperopia as the preponderant refractive error [24,28]. In some other studies $[16,25]$ myopia was found as the most prevalent. Similar to this study, few studies had reported astigmatism as the most frequent type of refractive error in children with disabilities $[21,23]$. These variations may be partly due to differences in the operational definition for classification of refractive errors, and partly from the age distribution of the study participants. For instance,Turkish study 30 that reported hyperopia as the leading refractive error had included children less than 5 years, but the lower age limit for this study was 5 years. In general, children age $<5$ years are usually hyperopic due to the relatively short axial length of their eyeball [10].

Only $9.9 \%$ of the children communicated the presence of eye symptoms, however on ocular examination a significant proportion of the children with disabilities had ocular disorders. Furthermore, only $6.8 \%$ of the study participants did have previous oculo-visual assessment. This explains the explicably poor communication of symptoms and high level of unmet oculo-visual needs among the study participants. Aghajiet al[29] in a cross-sectional study of children (5-15 years) with Down syndrome attending a special school in Enugu, Nigeria, found that despite the high prevalence of uncorrected refractive error $(76.4 \%)$ among these children, none of the children had ever had an ophthalmic assessment nor obtained a refractive correction. This may likely be due to the fact that the caregivers may have been overwhelmed with the other challenges of their primary disability and had no clue to the possibility of an ocular problem.

This is further worsened by the inability of these children to express and/ or relate to the presence of symptoms, as was also noted in our study. This highlights the need for an all-inclusive, integrated and comprehensive healthcare service for these children, possibly in their school environment, with appropriate referral for the further evaluation and management where necessary. The parents, caretakers and the teachers need to be sensitized and motivated for the regular ophthalmic examination of these children, even if the disability is not visual in nature. Protocols should be made regarding, mandatory vision screening at the time of admission in the schools, an annual comprehensive eye examination, early intervention and treatment if an ocular disorder is detected. 
Limitation- A major lacuna in this study is the inability to reach out to the children with disabilities who don't attend the special schools. Thus, there is a need for developing strategies for universal screening of children with disabilities, either by aiming for universal education or by encouraging community based screening and rehabilitation camps for them.

\section{Conclusion}

The prevalence of ocular disorders is high in children with other disabilities. Majority of the ocular disorders are treatable. As the children with disabilities use their visual sense to compensate for their primary disability, an early ophthalmic intervention by an ophthalmic team at the point of enrolment into school, as well as a periodic ophthalmic evaluation by trained school teachers and school health officer for these children can help in the academic and social performance of these children. This may be efficiently delivered through a coordinated effort of governments, non-governmental agencies and public-spirited individuals, especially in resource poor countries.

\section{What this study adds to existing knowledge?}

- The ophthalmic problems of children with disabilities in this Southern part of Nigeria are similar to that elsewhere in the world.

- Neurologic dysgenesis may be playing a major role in the oculo-visual state of children with disabilities.

\section{Contribution details of the authors}

*Ernest I. Ezeh: contributed in study design, data collection, data analysis, and manuscript drafting.

*Chigozie I. Uzomba: contributed in study design, data collection, and manuscript drafting.

*Roseline N. Ezeh: contributed in data collection, and manuscript drafting.

*Stanley Onyemelonu: contributed in data collection and manuscript drafting.

This manuscript has been read and approved by all the authors, and affirm that it represents honest work.

Funding: Nil, Conflict of interest: Nil

Permission from IRB: Yes

\section{References}

1. Disability. [internet]. 2014 [cited 2015 Jan 14]; Available from: URL:http://www.en.m.wikipedia.org/
2. Disabilities. [internet]. 2004 [cited 2014 Jan 16]; Available from: URL: http://www. who.int/topics/ disabilities/en/

3. Joshi RS, Somani AA. Ocular disorder in children with mental retardation. Indian J Psychiatry. 2013 Apr; 55 (2):170-2. doi: 10.4103/0019-5545.111457.

4. Osaiyuwu AB, Ebeigbe JA. Prevalence of visual disorders in deaf children in Benin City. JNOA 2009; 15: 20-23.

5. Woodhouse JM. Investigating and managing the child with special needs. Ophthalmic Physiol Opt. 1998 Mar; 18 (2):147-52.

6. Das M, Spowart K, Crossley S, et al. Evidence that children with special needs all require visual assessment. Arch Dis Child. 2010 Nov; 95(11):888-92. doi: 10.1136/adc.2009.159053. Epub 2010 Jul 20.

7. Woodhouse JM, Davies N, McAvinchey A, et al. Ocular and visual status among children in special schools in Wales: the burden of unrecognized visual impairment. Arch Dis Child. 2014 Jun;99(6): 5004. doi: 10.1136/ archdischild- 2013- 304866. Epub 2013 Nov 26.

8. El-Hazmi MAF. Early recognition and intervention for prevention of disability and its complications. Eastern Med Health J 1997; 3(1):154-161.

9. Bodack M. Eye and vision assessment of children with special needs in an interdisciplinary school setting. Opt Vis Dev 2011; 42(3):220-26.

10.Taylor D, editor. Normal and abnormal visual development: Paediatric Ophthalmology. Oxford UK: Blackwell Science; 1997; 13-28.

11. Salt A, Sargent J. Common visual problems in children with disability. Arch Dis Child. 2014 Dec;99 (12): 1163-8. doi: 10.1136/archdischild-2013-305267. Epub 2014 Aug 27.

12. Gurvinder K, Satish T, Mahesh J, Bhatti SM. Visual Function and Ocular Status in Children with Disabilities in Special Schools of Northern India. Journal of Clinical and Diagnostic Research. 2016; 10 (10): 1-4.doi:10. 7860 / JCDR/2016/23615.8742.

13. The United Nations Convention on the Rights of People with Disabilities: A guide for disabled people and disabled people's organizations. [internet]. 2002 


\section{Original Research Article}

[cited 2014 Jan 20]; Available from: URL:http:// www.un.org/ disabilities/convention/facts.shtml

14. Council for International Organizations of Medical Sciences. International Ethical Guidelines for Biomedical Research Involving Human Subjects. [internet]. 2002 [cited 2014 Jan 20]; Available from: https://globalhealthtrainingcentre.tghn.org/site_media/m edia/medialibrary/2011/04/CIOMS_International_Ethic al_Guidelines_for_Biomedical_Research_Involving_Hu man_Subjects.pdf

15. Oladejo MA, Oladejo SA. Educating Students with Disabilities in Nigeria: Some Challenges and Policy Implications. European Journal of Humanities and Social Sciences 2011; 3(1): 128-139.

16. Adedayo OA, Samuel OW. Ophthalmic manifestations of children with Down's syndrome in Port Harcourt, Nigeria. Clinical Ophthalmology 2012:6 1859-64.doi: 10.2147/OPTH.S36685.

17. Tsao WS, Hsieh HP, Chuang YT, Sheu MM. Ophthalmologic abnormalities among students with cognitive impairment in Eastern Taiwan: The special group with undetected visual impairment. J Formos Med Assoc 2017;116(5):345-50.doi: 10.1016/j.jfma. 2016. 06.013.

18. Akinci A, Oner $\mathrm{O}$, Bozkurt $\mathrm{OH}$, et al. Refractive errors and ocular findings in children with intellectual disability: a controlled study. J AAPOS. 2008 Oct;12 (5): 477-81. doi: 10.1016/j.jaapos.2008.04.009. Epub 2008 Jul 2.

19. Charmaine BS, Bindu N, Raju KV, Merin G. Ocular Associations in Children with Developmental Delay. Kerala Journal of Ophthalmology 2011; 23 (4): $367-71$.

20. Liza-Sharmini AT, Azlan ZN, Zilfalil BA. Ocular findings in Malaysian children with Down syndrome. Singapore Med J. 2006 Jan;47(1):14-9.
21. Kim JH, Hwang JM, Kim HJ, et al. Characteristic ocular findings in Asian children with Down syndrome. Eye (Lond). 2002 Nov;16(6):710-4. DOI:10.1038/sj. eye. 6700208

22. Wong V, Ho D. Ocular abnormalities in Down syndrome: an analysis of 140 Chinese children. Pediatr Neurol. 1997 May;16(4):311-4.

23. Hanioðlu-Kargý S, Köksal M, Tomaç S, Hayri Uðurbap S. Ophthalmologic abnormalities in children from a Turkish school for the deaf. The Turkish Journal of Pediatrics 2003; 45(1): 39-42.

24. Hanan HA, Amira A. Abdel A, Hala TE, Moataz EG Akmal R. Ocular Findings and Management in Egyptian Children with Down syndrome. Journal of American Science 2011; 7(4):782-88.

25. Mwanza JC, Nkidiaka CM, Kayembe DL, et al. Ophthalmologic abnormalities in mentally retarded. Bull Soc BelgeOphtalmol. 2000;(277):75-8.

26. Gogate P, Freya RS, Jitesh K, Hemant D, Madan D, Clare G. Ocular disorders in children with learning disabilities in special education schools of Pune, India. Indian J Ophthalmol 2011;59(3):223-8.doi: 10.4103/ 0301-4738. 81036.

27. Gogate P, Rishikeshi N, Mehata R, et al. Visual impairment in the hearing impaired students. Indian $\mathrm{J}$ Ophthalmol. 2009 Nov-Dec;57(6):451-3. doi: 10.4103/ 0301-4738.57155.

28. Derek DM, Stemen DP, Craig H, Anil KL. Ocular findings in children with congenital sensorineural hearing loss. Arch Otolanyngol Head Neck Surg 2002; 128 (11):1303-6.

29. Aghaji AE, Lawrence L, Ezegwui I, Onwasigwe E, Okoye O, Ebigbo P,et al. Unmet visual needs of children with down syndrome in an African population: Implications for visual and cognitive development. Eur JOphthalmol2013;23(3):394-8.doi:10.5301/ejo.5000222

How to cite this article?

Ernest E. I, Chigozie U. I, Roseline E. N, Stanley O. Ocular status of children with disabilities in special schools in southern district of Cross River State, Nigeria. Trop J Ophthalmol Otolaryngol.2019;4(2):119125.doi:10.17511/jooo.2019.i02.09 